\title{
Erratum to: Genomics of Premature Atherosclerotic Vascular Disease
}

\author{
David Seo • Pascal Goldschmidt-Clermont • \\ Omaida Velazquez • Gary Beecham
}

Published online: 21 July 2010

(C) Springer Science+Business Media, LLC 2010

\section{Erratum to: Curr Atheroscler Rep}

\section{DOI 10.1007/s11883-010-0104-9}

Seo D, Goldschmidt-Clermont P, Velazquez O, Beecham G: Genomics of Premature Atherosclerotic Vascular Disease. Curr Atheroscler Rep 2010, 12:187-193.

This article was published in the May 2010 issue of Current Atherosclerosis Reports (volume 12, issue 3). The name of the second author was spelled incorrectly. The name should have been listed as Pascal Goldschmidt-Clermont.

The online version of the original article can be found at http://dx.doi. org/10.1007/s11883-010-0104-9.

D. Seo $(\bowtie) \cdot$ G. Beecham

University of Miami Miller School of Medicine,

1501 NW 10th Ave, 809 Biomedical Research Building,

Miami, FL 33136, USA

e-mail: dseo@med.miami.edu

G. Beecham

e-mail: gbeecham@med.miami.edu

P. Goldschmidt-Clermont

University of Miami Miller School of Medicine,

1600 NW 10th Ave, Rosensteil Medical Science Building,

Miami, FL 33136, USA

e-mail: pgoldschmidt@med.miami.edu

O. Velazquez

University of Miami Miller School of Medicine,

3016 Holtz Center,

Miami, FL 33136, USA

e-mail: ovelazquez@med.miami.edu 